\title{
Changes in the kinetics of the oxygen evolution reaction induced by oxide films at platinum electrodes
}

\author{
A.E. Bolzán and A.J. Arvia * \\ Instituto de Investigaciones Fisicoquímicas Teóricas y Aplicadas (INIFTA), Facultad de Ciencias Exactas, Universidad Nacional de la Plata, \\ Sucursal 4, Casilla de Correo 16, (1900) La Plata (Argentina)
}

(Received 20 December 1993; in revised form 17 February 1994)

\begin{abstract}
The oxygen evolution reaction (OER) was studied on different types of oxide-coated Pt electrodes in $1 \mathrm{M} \mathrm{H}_{2} \mathrm{SO}_{4}$. Polarization curves at "oxide-free" Pt electrodes show two Tafel regions with slopes of ca. $0.120 \mathrm{~V}$ per decade and $0.160 \mathrm{~V}$ per decade, whereas the polarization curves at Pt electrodes coated with an oxide film accumulated by potential cycling at $0.3 \mathrm{~V} \mathrm{~s}^{-1}$ between $0.95 \mathrm{~V}$ and $2.00 \mathrm{~V}$ show a single Tafel region. The value of the single slope decreases steadily as the thickness of the oxide film is increased to reach a limiting value of ca. $0.090 \mathrm{~V}$ per decade for oxide coating thicknesses greater than $2 \mathrm{~nm}$. Otherwise, hydrous Pt oxide coated electrodes show two Tafel regions; the first appears between 1.6 and $1.8 \mathrm{~V}$ with a Tafel slope which increases as the oxide coating thickness is increased; the second region in the 1.9-2.1 V range involves a Tafel slope of ca. $0.088 \mathrm{~V}$ per decade which is independent of the coating thickness. This electrochemical behaviour is interpreted in terms of different oxide layer structures in which a fast redox electrochemical system is involved. This system influences the kinetics of the OER, probably through the formation of an intermediate species at the outer hydrous Pt oxide layer involving oxidation states of Pt higher than $\mathrm{Pt}(\mathrm{IV})$.
\end{abstract}

\section{Introduction}

The presence of oxide films on metal electrodes, either at the monolayer level or as a homogeneous or heterogeneous oxide phase, can modify the kinetics of a number of electrochemical reactions. For instance, the electro-oxidation of small organic molecules, such as $\mathrm{CO}$, is influenced by a submonolayer of $\mathrm{O}$ atoms on $\mathrm{Pt}[1,2]$. In addition, the evolution of $\mathrm{O}_{2}$ and $\mathrm{Cl}_{2}$, as well as other electrocatalytic reactions at high positive potential [3], also takes place on oxide-coated Pt electrodes.

The characteristics of $\mathrm{Pt}$ oxide coatings depend strongly on whether they are formed under either potentiostatic [4-7] or potential cycling [8-10] condition. Thick $\mathrm{Pt}$ oxide coatings have been described as duplex structures consisting of an inner quasi-two-dimensional $\mathrm{O}$ adatom monolayer and a thick outer hydrous Pt oxide layer. The behaviour of the outer layer depends strongly on the preparation procedure [11]. Thick hydrous Pt oxide layers, grown by applying

\footnotetext{
${ }^{\star}$ To whom correspondence should be addressed.
}

appropriate periodic potential routines in acids, behave as a gel-like material $[9,11]$.

The formation of both thin $(<2 \mathrm{~nm}) \mathrm{Pt}$ oxide layers by potential cycling between 0.9 and $2.00 \mathrm{~V}$ at $0.3 \mathrm{~V}$ $\mathrm{s}^{-1}$ and thick hydrous oxide layers by potential cycling between 0.58 and $2.2 \mathrm{~V}$ at $100 \mathrm{~V} \mathrm{~s}^{-1}$ is accompanied by the simultaneous appearance of a fast reversible charge storage process [10]. The voltammetric behaviour of this type of oxide-coated Pt electrode is similar to that found for $\mathrm{Rh}$ electrodes which have been subjected to a vigorous potential treatment in the $\mathrm{O}$ electrosorption potential range [12]. In this case, the presence of a fast redox system in the oxide layer reduces the Tafel slope for the oxygen evolution reaction (OER) in acid at room temperature [12]. Accordingly, from the standpoint of electrocatalysis, it appears interesting to compare the kinetics of the OER in acid on different types of oxide-coated Pt electrodes.

\section{Experimental}

The working electrode consisted of Pt wires (Johnson Matthey, $99.998 \%$ purity) of real area about $1 \mathrm{~cm}^{2}$ 
sealed to soft glass tubings. The working electrode area was determined from the voltammetric charge of $\mathrm{H}$ atom electrosorption [13].

Each working electrode was polished with $1 \mu \mathrm{m}$ grit $\mathrm{Al}_{2} \mathrm{O}_{3}$ water suspension and then potentially cycled between $E_{\mathrm{c}}=0.050 \mathrm{~V}$ and $E_{\mathrm{a}}=1.45 \mathrm{~V}$ at $v=0.3 \mathrm{~V}$ $\mathrm{s}^{-1}$ to attain the corresponding stabilized voltammogram for $\mathrm{H}$ and $\mathrm{O}$ electrosorption processes. The working electrode potential was measured against a reversible hydrogen electrode (RHE) in the same solution. The reference electrode was connected to the rest of the cell by a conventional capillary tip to minimize ohmic drop. The counterelectrode was a platinum gauze. Runs were made in aqueous $1 \mathrm{M} \mathrm{H}_{2} \mathrm{SO}_{4}$ at $25^{\circ} \mathrm{C}$. The electrolyte solution was prepared from $\mathrm{H}_{2} \mathrm{SO}_{4}$ (Merck p.a., 97\%) and Milli-Q* water, and used under purified $\mathrm{N}_{2}$. The electrochemical set-up consisted of a Krohn-Hite function generator coupled to a potentiostat PAR-273, both controlled by an IBM 30-286 personal computer.

Polarization curves on different oxide-coated $\mathrm{Pt}$ electrodes were measured at potential scan rates $v$ usually lower than $0.005 \mathrm{~V} \mathrm{~s}^{-1}$ to approach closely steady state polarization conditions. The fulfilment of quasi-steady-state conditions was checked by performing potentiodynamic polarization runs at several potential sweep rates from $0.030 \mathrm{~V} \mathrm{~s}^{-1}$ downwards until no change in the Tafel plots was observed. This ensures that the measured Tafel plot is independent of the value of the potential sweep rate.

The following Pt electrodes were studied: (i) electrodes stabilized by potential cycling at $0.3 \mathrm{~V} \mathrm{~s}^{-1}$ between $0.05 \mathrm{~V}$ and $1.45 \mathrm{~V}$ which are identified as "oxide-free" electrodes, (ii) oxide-coated Pt electrodes prepared by galvanostatic anodization at $1 \mathrm{~mA} \mathrm{~cm} \mathrm{~cm}^{-2}$ (iii) oxide-coated $\mathrm{Pt}$ electrodes prepared by potential cycling between $E_{\mathrm{c}}^{\prime}=0.95 \mathrm{~V}$ and $E_{\mathrm{a}}^{\prime}=2.00 \mathrm{~V}$ at $v=$ $0.300 \mathrm{~V} \mathrm{~s}^{-1}$ and (iv) oxide-coated Pt electrodes prepared by potential cycling between $E_{\mathrm{c}}^{\prime}=0.58 \mathrm{~V}$ and $E_{\mathrm{a}}^{\prime}=2.2 \mathrm{~V}$ at $v=100 \mathrm{~V} \mathrm{~s}^{-1}$.

\section{Results}

The OER kinetics in $1 \mathrm{M} \mathrm{H}_{2} \mathrm{SO}_{4}$ changes considerably in going from an "oxide-free" $\mathrm{Pt}$ electrode to oxide-coated Pt electrodes. For these electrodes, the OER kinetics also depends on the type of $\mathrm{Pt}$ oxide coating.

The OER Tafel plot on a Pt electrode previously stabilized between $0.050 \mathrm{~V}$ and $1.45 \mathrm{~V}$ at $0.3 \mathrm{~V} \mathrm{~s}^{-1}$ (Fig. 1) shows two linear regions. The first extends from ca. $1.55 \mathrm{~V}$ to ca. $1.75 \mathrm{~V}$ with a slope $\left(b_{\mathrm{T}}\right)_{\mathrm{I}} \approx 0.120$ $V$ per decade, whereas the second region passes from ca. $1.90 \mathrm{~V}$ to ca. $2.15 \mathrm{~V}$ with a slope $\left(b_{\mathrm{T}}\right)_{\mathrm{II}} \approx 0.160 \mathrm{~V}$

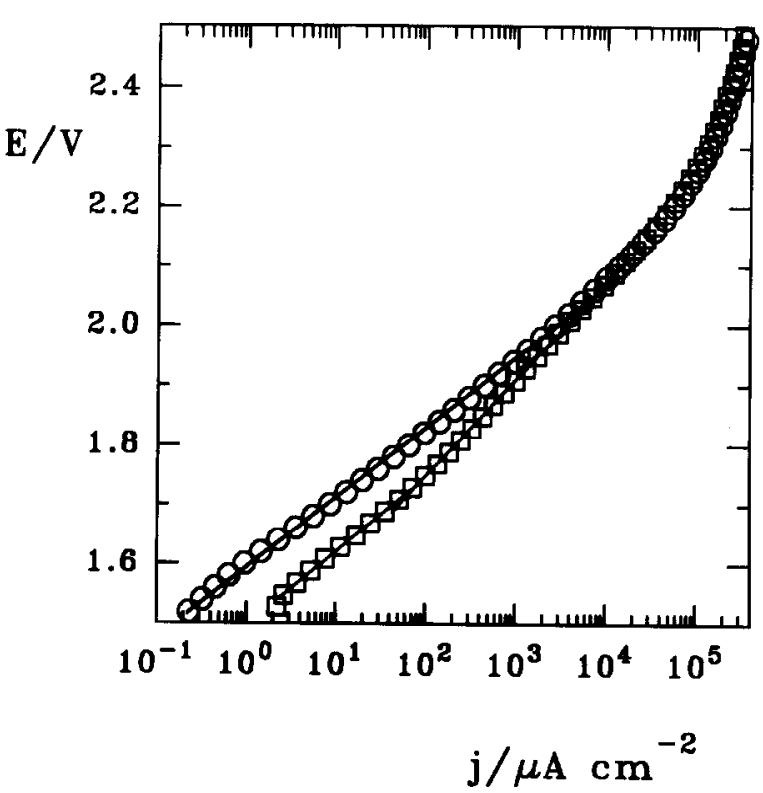

Fig. 1. Tafel plots for the OER on Pt in $1 \mathrm{M} \mathrm{H}_{2} \mathrm{SO}_{4}\left(v=1 \mathrm{mV} \mathrm{s}{ }^{-1}\right.$; temperature, $25^{\circ} \mathrm{C}$ ): $\square$ Pt electrode previously stabilized between $0.050 \mathrm{~V}$ and $1.45 \mathrm{~V}$ at $0.3 \mathrm{~V} \mathrm{~s}^{-1} ; \mathrm{O}$ Pt electrode previously anodized at $1 \mathrm{~mA} \mathrm{~cm}-2$ per $100 \mathrm{~s}$.

per decade. The Tafel plot changes markedly at oxidecoated Pt electrodes. Thus, for an oxide-coated Pt electrode prepared by holding the current at $1 \mathrm{~mA} \mathrm{~cm}$ for $100 \mathrm{~s}$, the Tafel plot at $v=1 \mathrm{mV} \mathrm{s}^{-1}$ presents a single straight line region from ca. $1.6 \mathrm{~V}$ to $2.0 \mathrm{~V}$ with a slope $b_{\mathrm{T}} \approx 0.120 \mathrm{~V}$ per decade (Fig. 1) irrespective of $v$, for $v \leq 3 \mathrm{mV} \mathrm{s}^{-1}$, in agreement with previously published steady-state data [14]. The value of $j_{0}$ extrapolated at $E=1.23 \mathrm{~V}$, the reversible potential of the $\mathrm{O}_{2}$ electrode in the solution at $25^{\circ} \mathrm{C}$, about $7.7 \times$ $10^{-10} \mathrm{~A} \mathrm{~cm}^{-2}$, a figure which is also in good agreement with values reported in the literature [15].

The OER kinetics in $1 \mathrm{M} \mathrm{H}_{2} \mathrm{SO}_{4}$ on Pt electrodes coated with a potentiodynamically produced oxide layer depends on the characteristics of the applied potential routine. Thus $\mathrm{Pt}$ oxide layer coatings which are less than $2 \mathrm{~nm}$ thick, formed by potential cycling between $E_{\mathrm{c}}^{\prime}=0.95 \mathrm{~V}$ and $E_{\mathrm{a}}^{\prime}=2.00 \mathrm{~V}$ at $v=0.3 \mathrm{~V} \mathrm{~s}^{-1}$ for a time $0 \mathrm{~s} \leq \tau \leq 900 \mathrm{~s}$, exhibit a fast reversible electrochemical system [10]. The contribution of this system increases with $\tau$ [10]. For this type of electrode, the OER Tafel plots show a single straight line for $\tau>0$ (Fig. 2) with a $v$-independent slope $b_{\mathrm{T}} \approx 0.090 \mathrm{~V}$ per decade, and $j_{0}=8 \times 10^{-10} \mathrm{~A} \mathrm{~cm}^{-2}$ for $\tau=300 \mathrm{~s}$ (Fig. 3). The value $b_{\mathrm{T}} \approx 0.090 \mathrm{~V}$ per decade is the lowest attainable at oxide-coated $\mathrm{Pt}$ electrodes. Conversely, for $\tau=0$, Tafel plots from $E=1.5 \mathrm{~V}$ upwards always exhibit two linear portions with $v$-dependent slopes (Fig. 4). 


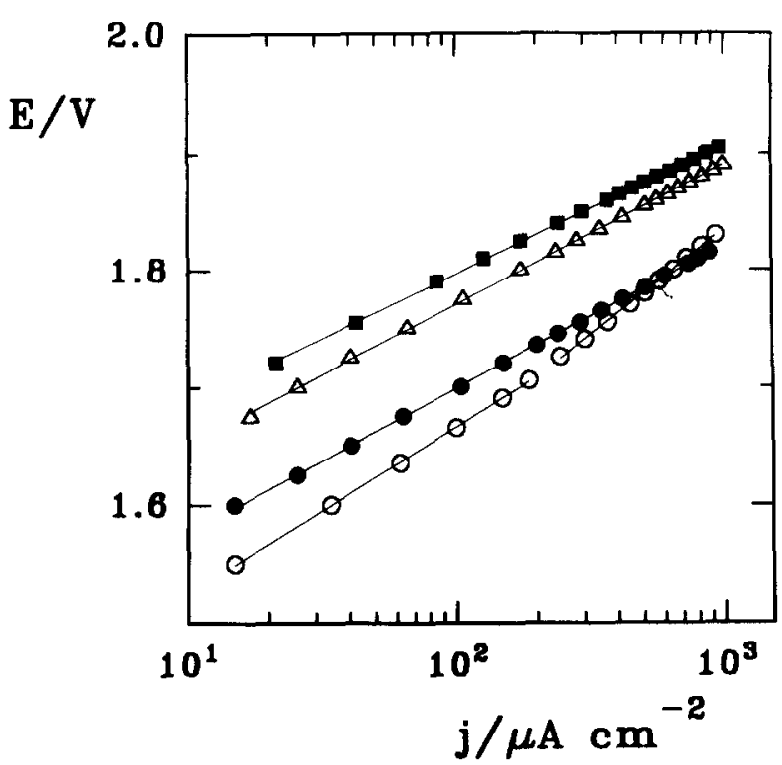

Fig. 2. Tafel plots for the OER on $\mathrm{Pt}$ in $1 \mathrm{M} \mathrm{H}_{2} \mathrm{SO}_{4}$ (the $\mathrm{Pt}$ electrode was previously cycled at $v=0.3 \mathrm{~V} \mathrm{~s}^{-1}$ between $0.95 \mathrm{~V}$ and $2.00 \mathrm{~V}$ in $1 \mathrm{M} \mathrm{H}_{2} \mathrm{SO}_{4}$ ) $\bigcirc \tau=0 \mathrm{~s} ; \bullet \tau=30 \mathrm{~s} ; \Delta \tau=60 \mathrm{~s} ; \quad \tau=300$ s. $v=3 \mathrm{mV} \mathrm{s}^{-1}$; temperature, $25^{\circ} \mathrm{C}$.

Similar experiments were performed with Pt electrodes coated with a hydrous oxide layer which was produced by potential cycling between $0.58 \mathrm{~V}$ and 2.2 $\mathrm{V}$ at $v=100 \mathrm{~V} \mathrm{~s}^{-1}$ for $30 \mathrm{~s} \leq \tau \leq 900 \mathrm{~s}$ [8], and finally potential stepped to $1.6 \mathrm{~V}$. The OER Tafel plots (Fig. 5) show two linear portions with slopes of $0.130 \mathrm{~V} \leq$

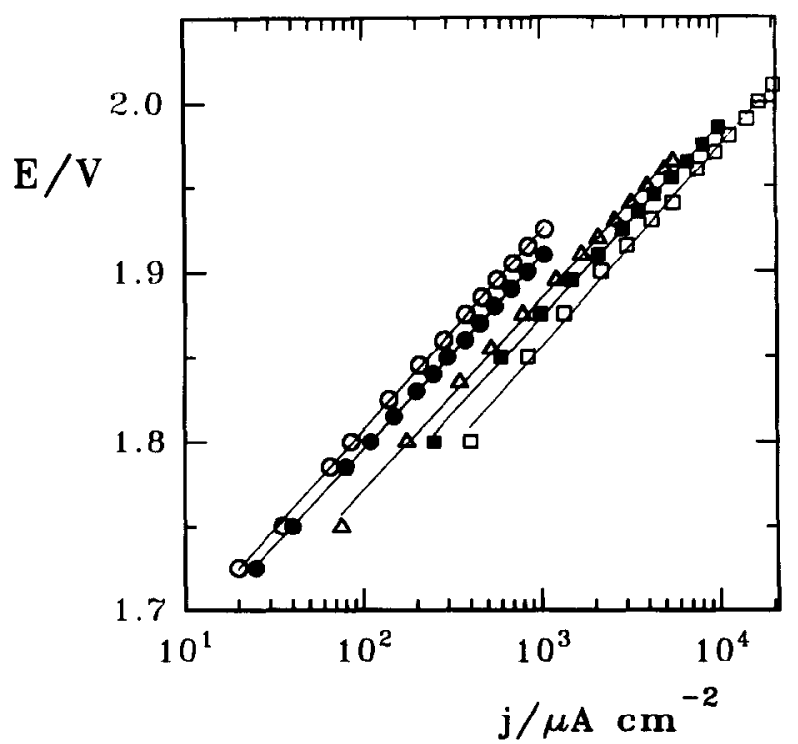

Fig. 3. Tafel plots recorded for the OER on $\mathrm{Pt}$ in $1 \mathrm{M} \mathrm{H}_{2} \mathrm{SO}_{4}$ (the $\mathrm{Pt}$ electrode was previously cycled at $v=0.3 \mathrm{~V} \mathrm{~s}^{-1}$ between $0.95 \mathrm{~V}$ and $2.00 \mathrm{~V}$ for $\tau=300 \mathrm{~s}: 0 v=1 \mathrm{mV} \mathrm{s}^{-1} ; \quad v=3 \mathrm{mV} \mathrm{s}^{-1} ; \Delta v=10$ $\mathrm{mV} \mathrm{s}{ }^{-1} ; \quad v=0.1 \mathrm{~V} \mathrm{~s}^{-1} ; \square v=0.3 \mathrm{~V} \mathrm{~s}^{-1}$. Temperature, $25^{\circ} \mathrm{C}$.

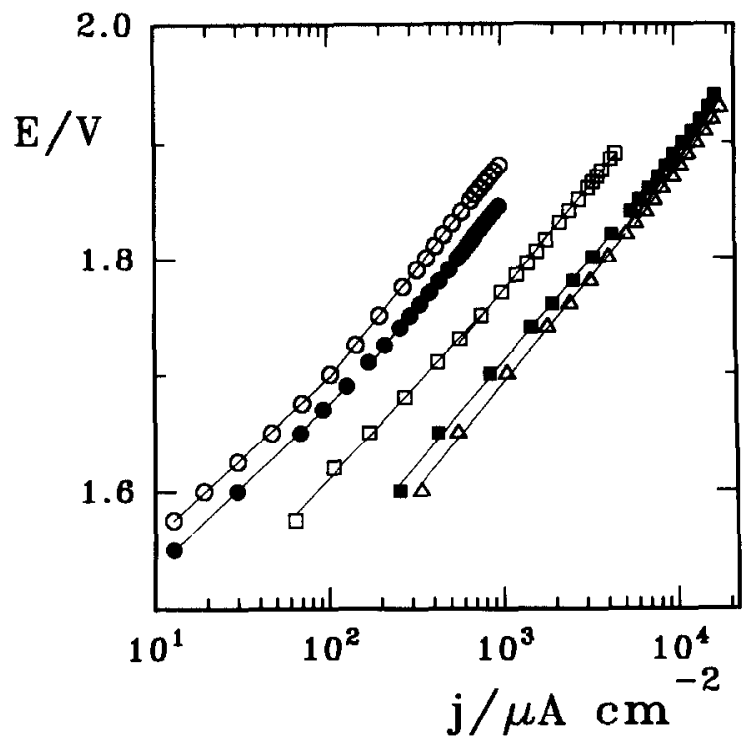

Fig. 4. Tafel plots for the OER on Pt in $1 \mathrm{M} \mathrm{H}_{2} \mathrm{SO}_{4}$ in the absence of the fast redox system $(\tau=0): O v=0.1 \mathrm{mV} \mathrm{s}^{-1} ; v=3 \mathrm{mV} \mathrm{s}^{-1}$; $\square v=30 \mathrm{mV} \mathrm{s}^{-1} ; \quad v=0.1 \mathrm{~V} \mathrm{~s}^{-1} ; \Delta v=0.3 \mathrm{~V} \mathrm{~s}^{-1}$. Temperature, $25^{\circ} \mathrm{C}$.

$\left(b_{\mathrm{T}}\right)_{\mathrm{I}} \leq 0.140 \mathrm{~V}$ per decade in the range 1.7-1.9 $\mathrm{V}$ and $0.080 \mathrm{~V} \leq\left(b_{\mathrm{T}}\right)_{\mathrm{II}} \leq 0.090 \mathrm{~V}$ per decade in the range 1.9-2.05 V; the corresponding values of $j_{0}$ were $3 \times$ $10^{-9} \mathrm{~A} \mathrm{~cm}^{-2}$ and $2 \times 10^{-11} \mathrm{~A} \mathrm{~cm}^{-2}$.

According to earlier reported data [11], hydrous oxide films accumulated during $\tau \geq 600 \mathrm{~s}$ are easily

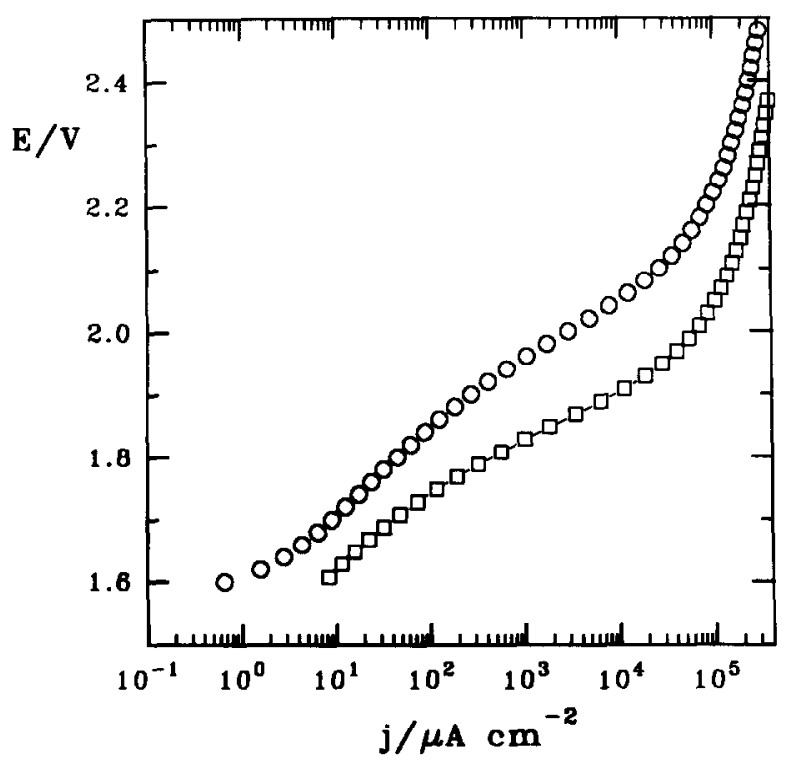

Fig. 5. Tafel plots for the OER at oxide-coated $\mathrm{Pt}$ in $1 \mathrm{M} \mathrm{H}_{2} \mathrm{SO}_{4}$. Oxide film accumulated by potential cycling between $0.58 \mathrm{~V}$ and 2.20 $\mathrm{V}$ at $v=100 \mathrm{~V} \mathrm{~s}^{-1}$ for $\tau=300 \mathrm{~s}(\mathrm{O})$ and $\tau=900 \mathrm{~s}(\square) . v=0.001 \mathrm{~V}$ $\mathrm{s}^{-1}$; temperature, $25^{\circ} \mathrm{C}$. 


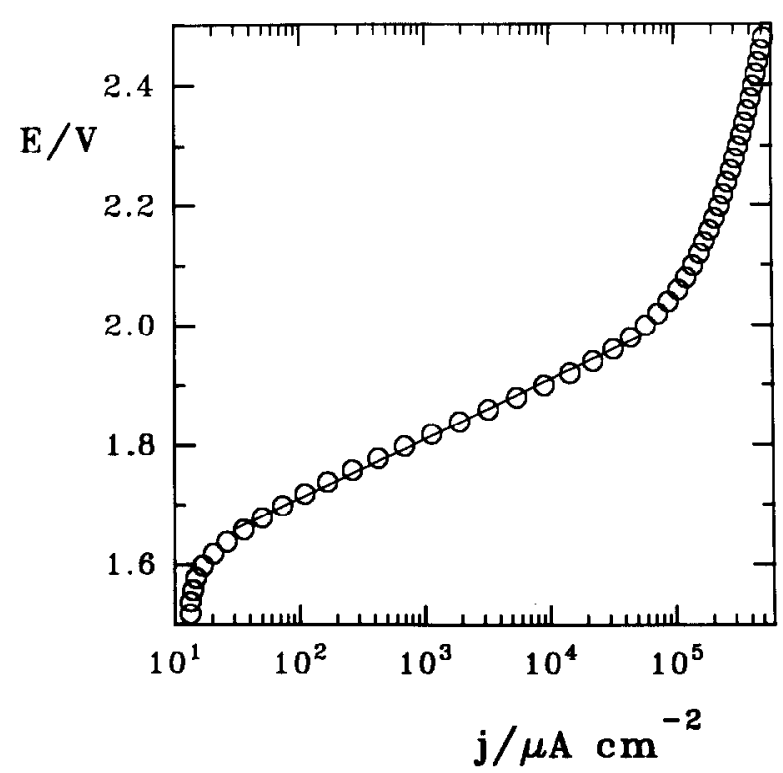

Fig. 6. Tafcl plots for the OER on oxide-coated $\mathrm{Pt}$ in $1 \mathrm{M} \mathrm{H}_{2} \mathrm{SO}_{4}$. The Pt hydrous oxide layer initially present on the electrode has been detached at $2.5 \mathrm{~V}$. Temperature, $25^{\circ} \mathrm{C}$.

detached from the Pt substrate at potentials above 2.00 V. When oxide coating detachment occurs, the OER Tafel plot, resulting from the $\mathrm{Pt}$ electrode with the residual oxide coating, shows a single slope $b_{\mathrm{T}} \approx 0.090$ $\mathrm{V}$ per decade in the range $1.75-2.0 \mathrm{~V}$ (Fig. 6).

Kinetic data derived from Tafel plots are summarized in Table 1. The appearance of two Tafel slopes at Pt electrodes coated with a thick oxide layer agrees qualitatively with the behaviour already reported in the literature [11], although the Tafel slope observed in the upper potential region is higher than the valuc of 0.040 $\mathrm{V}$ per decade reported elsewhere [11]. Values of $j_{0}$ extrapolated to $1.23 \mathrm{~V}$ show a decrease from ca. $10^{-8}$ $\mathrm{A} \mathrm{cm}-2$ in the low potential region to ca. $10^{-11} \mathrm{~A}$ $\mathrm{cm}^{-2}$ in the high potential region. The single Tafel slope, either $b_{\mathrm{T}}=0.120 \mathrm{~V}$ per decade obtained for galvanostatic anodized Pt or $b_{\mathrm{T}}=0.090 \mathrm{~V}$ per decade for potential cycled $\mathrm{Pt}$, approaches a value of $j_{0} \approx 10^{-10}$ $\Lambda \mathrm{cm}^{-2}$. This figure agrecs with that reported for $\mathrm{Pt}$ electrodes covered with oxide films of different thicknesses grown under galvanostatic conditions [14]. It should be mentioned, however, that higher $j_{0}$ values, such as $j_{0}=1.3 \times 10^{-9}$ and $j_{0}=8.5 \times 10^{-9} \mathrm{~A} \mathrm{~cm}-1$ under galvanostatic [16] and potentiostatic [17] conditions, have also been reported for the OER at $\mathrm{Pt}$ electrodes.

\section{Discussion}

The strong influence of the type of Pt oxide coating on the OER kinetics (Table 1) indicates that its initiation at a supposedly bare Pt electrode involves the simultaneous occurrence of its own oxide-coating formation reaction and the OER itself [18]. This means that the characteristics of the oxide layer, either previously formed or produced during the OER, should influence the OER kinetics. This fact can explain the appreciable variation in the OER kinetic data on $\mathrm{Pt}$ electrodes reported in the literature [14], as these electrodes are usually prepolarized either at constant current or potential to obtain a reproducible response. These pretreatments may produce oxide coatings of different electrochemical characteristics. However, it was concluded that oxidized Pt electrodes, compared with other metal oxide electrodes, behave as unsatisfactory electrocatalysts for the OER owing to the formation of rather poorly conducting $\mathrm{Pt}$ oxide films. Furthermore, the rate of the OER on $\mathrm{Pt}$ in acid decreases exponentially with the Pt oxide film thickness [14].

Several mechanisms have been proposed for the OER on Pt in acids [11,19-22], but the role played by Pt oxide coatings in the reaction is still unclear. Therefore the dependence of the OER kinetics on the his-

TABLE 1

Pularization data for oxygen evolution at different oxide-coated $\mathrm{Pt}$ electrodes

\begin{tabular}{llcc}
\hline Electrode pretreatment & Potential range $/ \mathrm{V}$ & $10^{9} j_{0}(E=1.23 \mathrm{~V}) / \mathrm{A} \mathrm{cm}^{-2}$ & $b_{T} / \mathrm{V} \mathrm{per} \mathrm{decade}$ \\
\hline "Oxide-free" $\mathrm{Pt}$ & $1.55-1.75$ & 6.75 & $0.120 \pm 0.005$ \\
& $1.90-2.15$ & 59.6 & $0.160 \pm 0.005$ \\
Galvanostatic anodization & $1.6-2.00$ & 0.77 & $0.120 \pm 0.005$ \\
$(1 \mathrm{~mA} \mathrm{~cm}-2,100 \mathrm{~s})$ & & & $0.090 \pm 0.005$ \\
Triangular potential cycling & $1.55-2.10$ & 0.8 & \\
$\left(0.95-2.00 \mathrm{~V}, v=0.3 \mathrm{~V} \mathrm{~s}^{-1}, 600 \mathrm{~s}\right)$ & & 3.5 & $0.135 \pm 0.005$ \\
Triangular potential cycling & $1.65-1.85$ & 0.036 & $0.090 \pm 0.005$ \\
$\left(0.58-2.22 \mathrm{~V}, v=100 \mathrm{~V} \mathrm{~s}^{-1}, 300 \mathrm{~s}\right)$ & $1.85-2.10$ & 78 & $0.140 \pm 0.005$ \\
Triangular potential cycling & $1.60-1.75$ & 0.16 & $0.090 \pm 0.005$ \\
$\left(0.58-2.2 \mathrm{~V}, v=100 \mathrm{~V} \mathrm{~s}^{-1}, 900 \mathrm{~s}\right)$ & $1.75-1.95$ & & \\
\hline
\end{tabular}


tory of oxide-coated $\mathrm{Pt}$ electrodes can be discussed, considering the possible structure of the oxide films formed under the different conditions.

The value $b_{\mathrm{T}}=0.120 \mathrm{~V}$ per decade for the OER on Pt electrodes has been related to the first electron transfer step as the rate determining step [19]. The first reaction step has been formally assigned to the formation of $\mathrm{OH}$ adsorbed species:

$\mathrm{Pt}+\mathrm{H}_{2} \mathrm{O} \rightarrow \mathrm{Pt}(\mathrm{OH})+\mathrm{H}^{+}+\mathrm{e}^{-}$

where $\mathrm{Pt}$ stands for a reacting site on $\mathrm{Pt}$ and $\mathrm{Pt}(\mathrm{OH})$ is an $\mathrm{OH}$ adsorbate on $\mathrm{Pt}$. However, reaction (1) represents a simple formal equation in which interactions and topographic features are not considered. Furthermore, reaction (1) at $\mathrm{Pt}$ electrodes behaves as a reversible surface process which is followed by the formation of an oxide coating whose thickness reaches about a few monolayers. These processes take place at potentials considerably lower than the OER threshold potential [23].

At transition metal electrodes, a high oxidation state of metal ions in the oxide layer can be produced by increasing the applied potential $[20,21,24,25]$, leading to reversible redox systems in the oxide matrix itself. The presence of those reversible electrochemical systems in this type of oxide coating on $\mathrm{Pt}$ seems to be responsible for the OER single Tafel line with $b_{\mathrm{T}}=$ $0.090 \pm 0.005 \mathrm{~V}$ per decade. This type of oxide coating on Pt seems to be that which has been identified as $\alpha$ or type I Pt oxide [4,26,27].

Otherwise, the kinetics of the OER with a thick coating of hydrous oxide exhibit two Tafel slopes. This type of Pt oxide layer has currently been identified as $\beta$ or type II oxide $[4,26,27]$. The fact that the first Tafel region (1.5-1.8 $\mathrm{V}$ range) has $b_{\mathrm{T}} \approx 0.15 \mathrm{~V}$ per decade, whereas the second Tafel region (1.8-2.1 $\mathrm{V}$ range) has $b_{\mathrm{T}} \approx 0.088 \pm 0.005 \mathrm{~V}$ per decade, indicates that, as the potential is increased, the OER kinetics is the same for all types of oxide-coated Pt electrode whenever the fast reversible redox system is present in the oxide matrix.

The value $b_{\mathrm{T}} \approx 0.090 \mathrm{~V}$ per decade cannot be explained by conventional reaction mechanisms [19]. Incidentally, this Tafel slope has previously been reported for $\mathrm{Pt}$ electrodes coated with a thin $\mathrm{Pt}$ oxide layer $(d \leq 6 \AA)$ [28] within the framework of a theoretical model for a tunnel probability contribution to the OER kinetics. This proposed model, which implies an increase of $b_{\mathrm{T}}$ with $d$, has been criticized as no OER Tafel slope change could be observed on increasing the oxide thickness [14].

The OER kinetics on electrodes covered with type I oxide appears to be independent of the oxide thickness (Fig. 3), and the value $b_{\mathrm{T}} \approx 0.090 \mathrm{~V}$ per decade implies a transfer coefficient $\alpha_{\hat{\mathrm{a}}} \approx 0.66$ assisting the OER in the anodic direction. This value of $\alpha$ has been related to a direct elastic tunnelling contribution to the OER kinetics through the oxide film [29].

Both type I and type II oxides should be present in the duplex-type structure assigned to the thick hydrous oxide coatings at $\mathrm{Pt}$ electrodes [30]. In this case, at a constant potential the current in the low overpotential range is higher than that measured for Pt electrodes coated with type I oxide. This effect can be related to an increase in the active surface area at electrodes coated with a thick hydrous oxide layer, and the Tafel slope of $0.140 \mathrm{~V}$ per decade found at low overpotentials probably arises because of a decrease in the concentration of the species entering the fast Pt redox couple as the oxide coating thickness is increased. However, as the potential is raised, $\mathrm{Pt}^{z+}$ species $(+5$ $\leq z \leq+6$ ) probably reach a constant surface concentration, and then the OER kinetics is the same as that of Pt electrodes coated with a thin oxide layer. At this stage, any kinetic resistance due to a concentration gradient of mediator species would disappear, and charge transfer processes would mainly proceed through a sort of a redox chain mechanism. Accordingly, the OER kinetics at Pt electrodes coated with a thick oxide layer may comprise a contribution of electron tunnelling at the thin inner type I oxide layer, and a slow simultaneous charge and proton transfer operating through a redox chain at the thick outer type II oxide layer. This explanation is consistent with the fact that, once the outer oxide layer has been detached (Fig. 6), a single low Tafel line with $b_{\mathrm{T}} \approx 0.080 \mathrm{~V}$ per decade is observed, as has already been described for Pt electrodes coated with type I oxide (Fig. 2). Hence, for Pt electrodes coated with thick oxide, the OER kinetics would be controlled by an electron and proton transfer reaction at the outer oxide coating at low overpotentials, whereas, as the applied potential exceeds a certain value, the reaction would be determined by the fast redox system in the oxide matrix. This means that the OER involves the participation of the fast redox system in the $\mathrm{Pt}$ oxide layer which is formed by potential cycling routines [10].

The preceding interpretation of the role played by the fast redox system in the OER on oxide-coated Pt electrodes is consistent with the conducting characteristics of other comparable fast redox reactions such as $\mathrm{Mn}^{3+} / \mathrm{Mn}^{2+}$ and $\mathrm{Ce}^{4+} / \mathrm{Ce}^{3+}$ in aqueous media [26]. Furthermore, the presence of intermediate Pt oxidation states in the OER provides a way of understanding the potential-relaxation characteristics of $\mathrm{Pt}$ electrodes which were previously anodized either above or below $1.85 \mathrm{~V}$ [31].

It should be mentioned that changes in the OER Tafel slope, which have been attributed either to the 
onset of resonance tunnelling [32] or to the intervention of a redox mediator step involving different oxidation states of $\mathrm{Pt}$ in the oxide film [33], are likely to be equivalent, as resonance tunnelling can be induced by high oxidation states of Pt ions at the oxide surface as reported by Conway et al. [31].

Finally, the above OER kinetic behaviour on $\mathrm{Pt}$ in acid qualitatively resembles that of oxide-coated $\mathrm{Rh}$ electrodes in $12 \mathrm{M} \mathrm{H}_{2} \mathrm{SO}_{4}$, as in this case a fast redox system can also be produced by applying similar potential routines [12]. Thus the fast redox system in the oxide matrix led to a decrease in the OER Tafel slope from $0.166 \mathrm{~V}$ per decade to $0.110 \mathrm{~V}$ per decade, a value which appeared to be almost independent of $v$. Conversely, in the absence of the fast redox system, the Tafel plots exhibit $v$-dependent slopes.

\section{Conclusions}

- The accumulation of a fast redox system built up on Pt oxide coatings by potential cycling influences the kinetics of the OER on oxide-coated Pt electrodes.

- Oxide coatings produced on Pt electrodes can be described either as predominantly type I oxide (thin coatings) or type I + type II oxides (thick coatings).

- Tafel plots for Pt electrodes coated with a thick hydrous oxide layer exhibit two linear regions. At low potentials $b_{\mathrm{T}} \approx 0.140 \pm 0.005 \mathrm{~V}$ per decade, whereas at high potentials $b_{\mathrm{T}} \approx 0.090 \pm 0.005 \mathrm{~V}$ per decade. The first Tafel region disappears once the thick outer oxide coating has detached. Hydrous oxide coatings determine the OER kinetics at low potentials. At high potentials, the processes at the inner thin oxide coating containing the fast redox system, probably involving $\mathrm{Pt}^{z+}$ species $(4 \leq z \leq 6)$, become rate controlling. At $\mathrm{Pt}$ coated with a thin oxide layer, electron tunnelling, which may account for the electronic conductivity through the oxide, probably contributes to the OER kinetics.

\section{Acknowledgements}

This work was financially supported by the Consejo Nacional de Investigaciones Científicas y Técnicas (CONICET) of Argentina and the Comisión de Investigaciones Científicas de la Provincia de Buenos Aires (CIC). AEB. is a Member of the Research Career of CIC.

\section{References}

1 R. Parsons and T. VanderNoot, J. Electroanal. Chem., 257 (1988) 70.

2 B.B. Damaskin and E. Kazarinov in J.O’M. Bockris, E.B. Yeager and B.E. Conway (Eds.), Comprehensive Treatise of Electrochemistry, Vol. 1, Plenum Press, New York, 1984.

3 B.E. Conway, Theory and Principles of Electrode Processes, Ronald Press, Ncw York, 1964.

4 S. Shibata, J. Electroanal. Chem., 89 (1978) 37.

5 S.D. James, J. Electrochem. Soc., 161 (1969) 1681.

6 M. Peuckert and H. Ibach, Surf. Sci., 136 (1984) 319.

7 M. Peuckert, F.P. Coenen and H.P. Bonzel, Electrochim. Acta, 29 (1984) 1305

8 L.D. Burke and M.B.C. Roche, J. Electroanal. Chem., 164 (1984) 315.

9 A.C. Chialvo, W.E. Triaca and A.J. Arvia, J. Electroanal. Chem., 146 (1983) 93.

10 A.E. Bolzán and A.J. Arvia, J. Electroanal. Chem., 341 (1992) 93.

11 L.D. Burke, M.B. Roche and W.A. O'Leary, J. Appl. Electrochem., 18 (1988) 781

12 C. Pallota, N.R. de Tacconi and A.J. Arvia, J. Electroanal. Chem., 122 (1981) 367.

13 R. Woods in A.J. Bard (Ed.) Electroanalytical Chemistry, Vol. 9, Dekker, New York, 1977.

14 A. Damjanovic, V.I. Birss and D.S. Boudreaux, J. Electrochem. Soc., 138 (1991) 2549.

15 A. Damjanovic and B. Jovanovic, J. Electrochem. Soc., 123 (1976) 374.

16 J.P. Hoare, J. Electrochem. Soc., 112 (1965) 602.

17 J.P. Hoare, J. Electrochem. Soc., 113 (1966) 846.

18 V.I. Birss and A. Damjanovic, J. Electrochem. Soc., 130 (1983) 1688 .

19 A. Damjanovic in J.O'M. Bockris and B.E. Conway (Eds.), Modern Aspects of Electrochemistry, Vol. 5, Butterworths, London, 1969, Ch. 5.

20 S. Trasatti, J. Electroanal. Chem. 115 (1980) 125.

21 A.C.C. Tseung and S.M. Jasem, Electrochim. Acta, 22 (1976) 501.

22 J.O'M. Bockris, J. Chem. Phys., 24 (1956) 817.

23 B.E. Conway, H. Angerslein-Kozlowska, F.C. Ho, J. Klinger, B. MacDougall and S. Gottesfeld, Discuss Faraday Soc., 56 (1973) 210.

24 B.E. Conway and P.L. Bourgault, Can. J. Chem., 38 (1960) 1557.

25 M. Hara, K. Asami, K. Hashimoto and T. Masumoto, Electrochim. Acta, 28 (1983) 1073.

26 A.T. Kuhn and T.H. Randle J. Chem. Soc. Faraday Trans. I, 81 (1985) 403.

27 B.E. Conway and G. Jerkiewicz, Extended Abstracts, Meeting of the Electrochemical Society, 1992.

28 J.W. Schultze and K.J. Vetter, Electrochim. Acta, 18 (1973) 889.

29 W. Schmickler, J. Electroanal. Chem., 84 (1977) 203.

30 M. Farebrother, M. Goledzinowski, G. Thomas and V.I. Birss, J. Electroanal. Chem., 297 (1991) 469.

31 B.E. Conway and T.C. Liu, Langmuir, 6 (1990) 268.

32 J.W. Schultze and M. Haga, Z. Phys. Chem. NF., 104 (1977) 73.

33 B.E. Conway and T.C. Liu, Proc. R. Soc. London Ser. A, 429 (1990) 375 . 